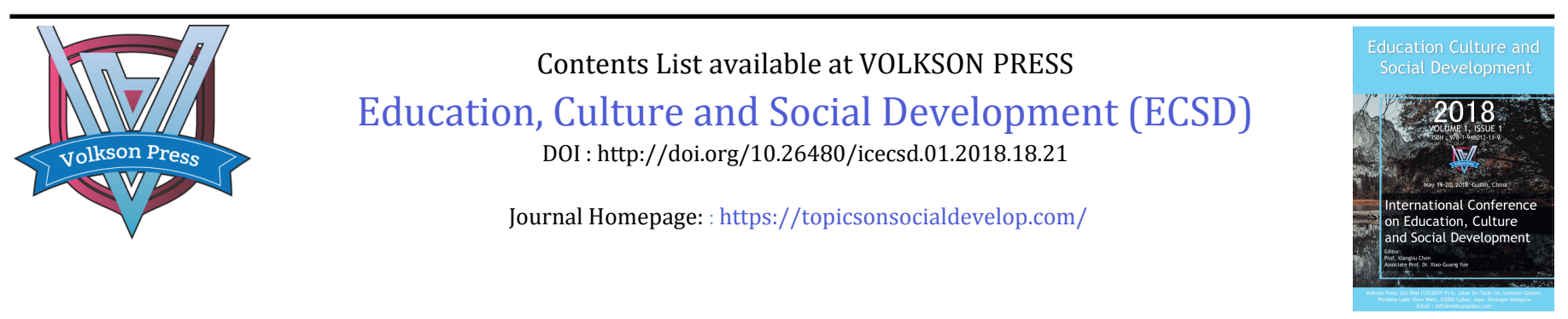

\title{
OPPORTUNITIES FOR PROMOTING WUSHU DUANWEI SYSTEM AT CONFUCIUS CLASSROOMS IN THE PHILIPPINES UNDER THE BELT AND ROAD INITIATIVE
}

\author{
Chen Sheng ${ }^{1}$ Xiao Rui ${ }^{2}$, Tang Jiping ${ }^{1}$, Yu Xiang1 \\ ${ }^{1}$ College of Physical Education, Chengdu University, Sichuan Chengdu, 610106, China. \\ ${ }^{2}$ College of Literature and Journalism, Sichuan University, Sichuan Chengdu, 610064, China. \\ *Corresponding Author Email: 787345913@qq.com
}

This is an open access article distributed under the Creative Commons Attribution License, which permits unrestricted use, distribution, and reproduction in any medium, provided the original work is properly cited

\section{ARTICLE DETAILS}

\section{Article History:}

Received 12 November 2017 Accepted 12 December 2017 Available online 1 January 2018

\section{ABSTRACT}

This essay examines problems in promoting Wushu (Chinese Martial Arts) at Confucius Institutes in the Philippines by the means of literature, interviews and field researches. Conclusions: Wushu is introduced to Confucius Classrooms in the Philippines, but it is not followed by the promotion of Duanwei (Ranking) System. Reasons include insufficient knowledge of top-level design of Wushu, lack of Duanwei teachers, inadequate evaluation and inspection organizations, underdeveloped curriculum, and unclear training objectives. Suggestions are as follows: to encourage the cooperation between Hanban and departments for organizing and promoting Wushu; to publicize policies and top-level design of Duanwei System; to make Duanwei System knowledge accessible to everyone; to establish a wide range of Duanwei examination and evaluation centers; to introduce MOOC to ease teacher shortage; to cultivate local teachers with professional Duanwei knowledge; to adopt to situations in the Philippines.

\section{KEYWORDS}

Belt and Road Initiative, Wushu Duanwei System, Confucius Classrooms, Cultural lessons.

\section{INTRODUCTION}

Wushu is the quintessence of China. The year of 1988 marked the implementation of the Duanwei System for ranking, which is widely accepted by Wushu lovers home and abroad. With efforts from Hanban, the Confucius Institute Headquarters founded in 2004 to provide teaching resources and services of Chinese language and culture for the world and promote diversity, Wushu becomes popular among students in other countries. The world was further impressed by the proposal of the Silk Road Economic Belt and 21st Century Maritime Silk Road (the Belt and Road Initiative) by president Xi Jinping during his visits to Central and Southeast Asia in September and October 2013. The Initiative sets policy, infrastructure, trade, financial, and people-to-people connectivity as priorities. On May 14, 2017, the Belt and Road Forum for International Cooperation launched Chinese Social Organizations' Action Plan for Stronger People-to-People Connectivity along the Belt and Road (20172020) [1]. To achieve stronger people-to-people connectivity, countries should expand cultural and academic exchanges and establish bilateral projects including culture years, art festivals and film festivals. Representing traditional sports in China, Wushu has had an impact on international communities. Promoting Duanwei System under the Belt and Road Initiative not only preserves Wushu culture, but also lifts Confucius Institutes and Classrooms as well as traditional sports in host countries to a new level.

Through literature, interviews, and field researches, the conditions and problems of Duanwei System under the Belt and Road Initiative are analyzed, and solutions are suggested in this essay for the reference to developing the Duanwei System overseas.

\section{ADVANTAGES: BELT AND ROAD INITIATIVE, DUANWEI SYSTEM OF WUSHU, AND STUDENTS}

\subsection{Opportunities Under the Belt and Road Initiative}

The Belt and Road Initiative is proposed by China and joined by countries along the routes, which follows the principle of wide consultation, joint contribution, shared benefits, openness and inclusion. Through effective communication, governments look into each other's strengths and make the most of them. The Belt and Road Initiative is integrated with existing strategies and programs, bringing mutual benefits and all-win results to China and participating countries, which also means economic, cultural, and tourism advancement as well as a broader international horizon for China.

In addition, Vision and Actions on Jointly Building Silk Road Economic Belt and 21st-Century Maritime Silk Road published in 2015 states that "we should carry out sports exchanges and support countries along the Belt and Road in their bid for hosting major international sports events", which shows the support for protecting and promoting traditional Chinese sports. Given that the Philippines is along the Maritime Silk Road, Confucius Classrooms should seize the opportunity of Belt and Road Initiative to develop Duanwei System and make it an excellent course [2].

\subsection{A Scientific System of Wushu Duanwei}

In December 2013, Wushu Management Center of General Administration of Sports of China, Chinese Wushu Association and Chinese Wushu Research Institute published Manual on the Duanwei System of Traditional Wushu (Revised Edition) [3]. "Duan" means phase, and "Wei" means position. Together, Duanwei System means a unified evaluation system to decide a Wushu practitioner's ranking position in certain phase of training. Textbook Series of Chinese Wushu Duanwei System is made up of four theory textbooks, 17 technical textbooks on 12 Quan styles, three weapon textbooks and general textbooks including Wushu for Fun (Preduan Textbook), Wushu Gongfa, and Wushu Self-defense [4]. The series covers the following aspects in a thorough and scientific way: technical actions of each Duan, theory examination, Level and Duan promotion, management and examination, application and appraisal, identification and conferment, certificate, badge and clothing. In terms of technical actions for example, punch, kick, grasp, position and wrestle are taught one by one from the first Duan to fifth Duan. The sixth Duan is about the 
combination of the above. It is a gradual and systematic study. Duanwei System not only applies to Wushu practitioners home and abroad, but also offers a scientific standard for Wushu management and publicity.

On May 6, 2014, General Administration of Sports of China and All-China Sports Federation issued the Ten-Year Plan to Promote Wushu Duanwei System [5]. Government programs, annual plans and financial budget are incorporated to create top-level design for Wushu. Government takes the lead, in coordination with Wushu associations and relevant promotion agencies home and abroad, to push Wushu culture forward. Besides, the Plan addresses the issues of schedule, location, target groups, promotion management and organization, and evaluation system. As for Wushu promotion, it specifies that overseas organizations should serve as channels. For example, Duanwei System lessons are introduced to Confucius Institutes and Classrooms via the cooperation with Hanban. It is hoped to establish Duanwei examination centers in 10 Confucius Institutes during pilot phase (2014-2015) and in more than a half of Confucius Institutes during popularization phase (2016-2020).

\subsection{Students at Confucius Classrooms}

By December 31, 2016, Hanban has established 512 Confucius Institutes and 1073 Confucius Classrooms in 140 countries and regions [6]. There are four Confucius Institutes and three Confucius Classrooms in the Philippines. All three Confucius Classrooms are set up in public schools affiliated with Department of Education to act as the center to spread Chinese language culture to 78 public schools of the whole region [7].

Students who attend Chinese class at Confucius Classrooms in the Philippines are mainly Filipinos between 13 and 16 years old. Adolescents are energetic, curious about new things and willing to learn. Doing sports can help them to shape self-discipline, teamwork spirit, achievement motivation, bravery and toughness [8]. In recent years, as China becomes more powerful and the relation between China and the Philippines goes back to normal, Philippine teenagers' demands for Chinese learning are increasing.

Similar to its American counterpart, the education mode in the Philippines emphasizes moral, intellectual, physical, aesthetic and labor education at the same time, which invests plenty of time and resources in cultural and sports lessons. Wushu, being one of the subjects to arise students' interest towards foreign cultures, can be included into daily cultural courses in combination of the local teaching mode.

\section{INTEGRATION: OVERLAP BETWEEN CLASSIFICATION OF DUANWEI SYSTEM AND STUDENT GROUPS AT CONFUCIUS CLASSROOMS}

Departments for organizing and promoting Wushu in China announced 2011 as Wushu Standardization Year, which marked the beginning of Duan promotion that features examination and is supplemented by evaluation. In terms of ranking, according to Manual on the Duanwei System of Traditional Wushu (Revised Edition), the professional levels of players can be graded from low to high as follows: Wushu for fun/preDuan (level 1-3), primary Duan (1st-3rd Duan), middle Duan (4th-6th Duan) and advanced Duan (7th-9th Duan). As for criteria, Wushu ethics and etiquettes are examined in pre-Duan phase. After learning basic Wushu skills and knowledge, those aged over 6 can be upgraded to level 1 after they pass the exam. Both level 1 and level 2 players have to study for another six months or more to be upgraded to the next level. Level 3 players can apply for the first Duan once they reach 11 years old and have studied level 3 skills and knowledge for over a year. Each Duan sets its own criteria. Duan certification is free for primary school students who apply for primary and the 1st Duan, secondary school students who apply for the 2nd Duan or below, and high school students who apply for the 3rd Duan or below. According to Ten-Year Plan to Promote Wushu Duanwei System, Wushu for Fun (Pre-Duan Textbook), Changquan, Yang-style Taijiquan, Chen-style Taijiquan and Wuzuquan are the recommended teaching materials for Wushu at Confucius Institutes.

Confucius Classrooms in the Philippines are founded at public schools affiliated with Department of Education. Public education system divides a secondary school into four grades and a high school into two grades.
Confucius Classrooms select one or two classes of students to learn Chinese among the best candidates. Chinese courses are split into four school years, namely the first to the fourth grades in secondary schools. Each week, those 13 to 16-year-old students study Chinese for at least four hours. What they learn at Confucius Classrooms is not only Chinese language but also Chinese culture including Wushu, paper cutting and calligraphy. If Pre-Duan (Level 1-3) and the 1st Duan is introduced into the cultural curriculum, it will agree with the progressiveness of Duanwei System and the four school years of Chinese learning.

\section{PROBLEMS: WUSHU AMONG CULTURAL LESSONS AT CONFUCIUS CLASSROOMS}

Founded in 2015, Confucius Classrooms in the Philippines pay close attention to cultural teaching. As a part of the cultural curriculum, Wushu witnesses healthy development. Despite of that, it still faces a series of problems especially in term of Duanwei System promotion.

\subsection{Numerous Learners with Mixed Athletic Ability}

In the Philippines, public schools affiliated with Department of Education open selective courses on Spanish, German, French, Italian, Japanese, Arabic and Chinese. Among those foreign languages, Chinese enjoys the fastest development, most extensive school coverage, and largest student group, thanks to the great support from Hanban and Confucius Institute at Angeles University Foundation (CIAUF). At every single one of the three schools with Confucius Classrooms, more than 200 students attend Chinese classes, with at least two classes per grade and over 40 people per class. Every student can sign up for Chinese class on a voluntary basis, but only those with a higher score overall will be admitted if there are too many applicants. Since academic performance accounts for a larger proportion of the assessment, the selected are not necessarily good athletes. Many of them do not fit for Wushu.

\subsection{Unfavorable Natural Environment and Insufficient Training Space}

The Philippines is a tropical island country consisting of over 7000 islands, which earns itself the reputation of "Thousand Island Country". Due to its geographic location, it suffers from typhoon and rainstorm in rainy season and drought and heat in dry season. The natural environment is less than satisfactory. At public schools affiliated with Department of Education in the Philippines, gymnasia and in particular the air-conditioned ones are hardly found on campus owing to a tight budget. Although two of the three schools that set up Confucius Classrooms have open-roof gymnasia, there are not enough facilities or space for teaching Wushu, which undermines the popularity and teaching effect.

\subsection{Incompetent Teaching Staff with Little Duanwei Knowledge}

Ten-Year Plan to Promote Wushu Duanwei System argues that each Confucius Institute should hire one or two Duanwei teachers to teach and promote Wushu. By now, four Confucius Institutes in the Philippines have not met the requirement. Only CIAUF employs one full-time Wushu teacher each year who nevertheless gives lessons at not only CIAUF but also three Confucius Classrooms under CIAUF. The heavy teaching load leaves no room for promotion work. According to the interview with Wushu teachers, what they learn in China covers little of Duanwei System. When they teach at Confucius Institutes and Classrooms, they seldom deal with Duanwei System and mainly introduce their specialties. In libraries at Confucius Institutes and Classrooms, there are Wushu textbooks, CDs and DVDs, none of which are concerned with Duanwei system, not to mention English versions.

\subsection{The Outdated Teaching Mode and Incomplete Curriculum}

Due to the lack of knowledge about Wushu top-level design as well as guidance and supervision from higher-level departments, Wushu courses at Confucius Classrooms center around Wubuquan, Changquan, Taijiquan and Wushu experiences. Wushu teachers arrange course content based on their personal skill knowledge and learning experience rather than follow a progressive manner. In addition, curriculum and archive management are underdeveloped, which makes it difficult for successors to follow up and arrange proper teaching content and agendas. 


\subsection{Unclear Training Objectives and Low Relearning Rate}

Although relevant departments have designed how to promote Duanwei System from the top level, the promotion runs slowly in practice. At present, the scholarship at Confucius Institutes and Classrooms only requires applicants to reach certain level of Chinese Proficiency Test, without enough policies favorable for students with specialty. Even though Wushu is taught at Confucius Classrooms, teachers have little idea about what goal to achieve. In addition, Wushu is undervalued. Most Wushu lessons serve as interest lectures and are mainly about Wushu appreciation. What students obtain is merely basic Wushu skills, which results in low relearning rate, especially after fourth grade in secondary school.

4.6 Limited Understanding of Top-level Design and Inadequate Examination and Evaluation Organizations

Literature review reveals that top-level design of Wushu is completed, especially after the proposal of Ten-Year Plan to Promote Wushu Duanwei System. As far as it goes, Confucius Classroom and Institute leaders and Wushu teachers have limited knowledge about Wushu promotion policies and new measures for they are far away from China, so they fail to take full advantage of Confucius Classrooms and Institutes to promote Wushu and Duanwei System. Not any Wushu promotion organization, Confucius Classroom or Institute is certified as Level I or II examination and evaluation agencies for Duanwei System. The lack of such agencies makes it difficult to promote Duanwei System smoothly.

\section{SOLUTIONS: CONTRIBUTION OF DUANWEI SYSTEM TO CULTURAL PROMOTION AT CONFUCIUS CLASSROOMS}

Manual on the Duanwei System of Traditional Wushu (Revised Edition) is a systematic and scientific guideline for Duanwei System and its promotion standards, which provides Confucius Classroom and Institute leaders and Wushu teachers with professional theory support. Besides, teaching Wushu based on Duanwei System stimulates students' desire to study Wushu and higher-level Duan knowledge because level promotion exams are a strong push.

\subsection{To Prepare Potential Candidates for Future Wushu Study and Improve Student Enrolment}

As China become economically strong, learning Chinese becomes a global new trend, which also arises Filipinos' interest towards their neighbor [9]. While theories on Duanwei System can be introduced via Wushu workshop as a part of the cultural curriculum, the teaching of Duanwei System is a long-term and systematic process that calls for Wushu practitioners' passion and perseverance. Therefore, the number of practitioners should be limited to magnify the teaching effect and ensure that they all acquire expertise.

As the medium of Chinese language and culture, Confucius Classrooms not only enable foreigners to better understand China but also nurture talents with Chinese proficiency for Confucius Institutes and other higher-level teaching organizations. By including Duanwei System knowledge into Confucius Classrooms, students are able to master Wushu skills and theories after a systematic and scientific study of four years. It becomes easier for upper-level teaching organizations to arrange Duanwei System classes for students with better Wushu proficiency.

\subsection{To Follow Laws of Nature and Set a Reasonable Learning Timetable}

The teaching of Duanwei System in the Philippines should take natural environment, facilities, location, studying habits into consideration to design a reasonable and feasible schedule for students to learn Wushu Duanwei [10]. For example, one Chinese class can be used for Duanwei teaching every two weeks. It is also suitable to put the courses after $4 \mathrm{pm}$ when the school is over for the day and host Wushu corners on campus. Regular publicity of Wushu culture and Duanwei lessons is necessary for motivating students to learn Wushu, thus extending Wushu's influence on campus.
5.3 To Popularize Duanwei System Courses and Improve the Curriculum

According to Ten-Year Plan to Promote Wushu Duanwei System, departments for organizing and promoting Wushu should invite Confucius Institutes and Classrooms to work together and share information on Duanwei rules and policies to eventually introduce Duanwei lessons into Confucius Institutes and Classrooms' cultural curriculum. The help from these departments can guide Wushu lesson organizers to choose content, train teachers, arrange timetables, and evaluate player level, which forms a scientific Wushu promotion system.

\subsection{To Introduce MOOC and the "Hemopoiesis" Plan to Ease Teacher Shortage}

Since this is only the early stage of Duanwei promotion, there are not enough teachers familiar with Duanwei System and will be not enough to meet the need of Confucius Institutes and Classrooms in a short time. Given the situation, Massive Open Online Course (MOOC) should be adopted. It can complement full-time Wushu teachers and volunteer Chinese teachers to make up for the shortage of professional Wushu teachers and help with the development of Wushu Duanwei System at Confucius Institutes and Classrooms [11].

What is more, the way that Wushu teachers are recruited at Confucius Institutes and Classrooms functions similar to transfusion. Hanban sends full-time Wushu teachers and volunteer Chinese teachers to teach Wushu after selecting and training, but the limited number of teaching staff can not satisfy the need for Wushu teachers in foreign countries. Therefore, talents should also be cultivated from within, like hemopoiesis. Batches of candidates are selected year by year from students who take Chinese courses and other locals who love Wushu. They receive standardized training to be equipped with sound knowledge about Duanwei System and qualified for the teaching position [12]. Although it is a long-term program that takes a lengthy period to go through the process and show results, it strikes at the root of Wushu teacher shortage and teachers' intercultural communication incompetence.

\subsection{To Clarify Training Objectives and Raise the Relearning Rate}

Wushu, a national treasure, has spread to foreign countries before Tang Dynasty, which contributes to China's exchanges with the outside world [13]. It is loved by people around the globe. As organizations for promoting Chinese culture and language, Confucius Institutes and Classrooms have responsibilities for spreading Wushu and Duanwei System. They should set the agenda, clarify training objectives, make Duanwei System knowledge accessible, improve Duanwei examination and evaluation of Wushu practitioners, and encourage practitioners to relearn.

\subsection{To Get Insights About Wushu Top-level Design and Optimize} Examination and Evaluation System

Departments responsible for organizing and promoting Wushu should strengthen communication and coordination with Hanban to deliver policy promotion information and top-level design to Confucius Institute and Classroom leaders in time. In addition, both parties should cooperate to equip teachers with Duanwei System knowledge and send them to Confucius Institutes and Classrooms. Hopefully, by 2020, more than a half of Confucius Institutes and Classrooms will establish examination and evaluation agencies as well as a Duan promotion system that is based on examination and supplemented by evaluation.

\section{CONCLUSIONS}

The implementation of Belt and Road Initiative brings China closer to the world. As cultural exchanges become more frequent, Confucius Institutes and Confucius Classrooms have responsibilities to spread Chinese culture and language. Wushu, as the quintessence of China, should be in the front line of cultural exchanges. Confucius Classrooms in the Philippines have unique advantages in spreading language and culture because they enter public schools affiliated with Department of Education and fit into the life of Filipinos. Seizing opportunities of the Belt and Road Initiative, Confucius Classrooms in the Philippines should incorporate Duanwei System lessons 
into the cultural curriculum in order to promote Duanwei System abroad in its principle of progressiveness.

\section{REFERENCES}

[1] BRFIC. 2017. Belt and Road Forum for International Cooperation. Xinhuanet www.news.cn.

[2] VAJBSREB. 2015. Vision and Actions on Jointly Building Silk Road Economic Belt and 21st-Century Maritime Silk Road. Xinhuanet www.news.cn, June 8.

[3] MDSTW. 2013. Wushu Management Center of General Administration of Sports of China, Chinese Wushu Association \& Chinese Wushu Research Institute. Manual on the Duanwei System of Traditional Wushu (Revised Edition) [Z].

[4] BHEP. 2010. Chinese Wushu Research Institute of General Administration of Sports of China. Wushu for Fun (Pre-duan Textbook) [M]. Beijing: Higher Education Press.

[5] GASCF. 2015. General Administration of Sports of China \& All-China Sports Federation. Ten-Year Plan to Promote Wushu Duanwei System (2014-2023) [Z]. 176.

[6] CIC. 2017. Confucius Institute Headquarters. Confucius Institutes/ Classrooms [EB/OL]. [June 1]. http://www.hanban.edu.cn/ confuciousinstitutes/node_10961.htm

[7] CIAUF. 2017. Confucius Institute at Angeles University Foundation [EB/OL]. [June 10]. http://www.auf.edu.ph/

[8] Yu, J. 1998. Development of Non-School Youth Sports in North America and Its Enlightment [J]. Sports \& Science, 19 (1), 21-23.

[9] Zhenmin, L. 2016. The Duterte visit signifies the full return of China and the Philippine's friendship back to its normal level [EB/OL]. [October 21]. http://world.huanqiu.com/hot/2016-10/9581076.html

[10] Ying, H. 2003. National Conditions in the Philippines [J]. International Data Information, (7), 24-30.

[11] Jun, L. 2016. Construction and Research on the Teaching Mode Flipped Classroom of MOOC [J]. Journal of Guangzhou Physical Education Institute, 36 (2), 121-123.

[12] Zhu, Z. 2013. A Brief Discussion About the Localization of Chinese Language Teaching in the Philippines [J]. Modern Chinese, 11, 84-86.

[13] Weiqiang, M. 2008. The Overseas Spread of Wuyi People and Chinese Wushu [J]. Journal of Wuyi University (Social Science Edition), 10 (1), 1215.

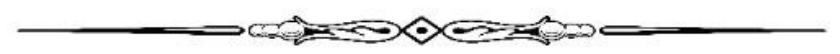

